\title{
The Structural Strengthening of a Masonry Heritage Shop House using Glass Fibre Based Materials
}

\author{
Kribanandan Gurusamy Naidu
}

JTK Consult Sdn Bhd, Kuala Lumpur, Federal Territory, Malaysia, drkribangn@jtkconsult.com.my

\begin{abstract}
A two-storey masonry pre-war shop house in Taiping, Malaysia was badly affected by construction being undertaken at an adjacent lot. The building was in a serious state of disrepair and on the verge of collapse at the time of the investigation and temporary propping and a stoppage of adjacent works had to be imposed. For the remedial intervention a rapid approach was critical with materials and methodologies selected to incur minimum additional impacts on the building in terms of physical works and with flexibility on site. Several innovative techniques developed for the structural intervention of masonry buildings was considered. In this case the masonry wall cracks were repaired by a stitching method using the glass fiber rod maperod $g$ which was considered a suitable material due to the compatibility of modulus of elasticity $(40,800 \mathrm{~N} / \mathrm{mm} 2)$ to the lime mortar, having good tensile strength of $760 \mathrm{~N} / \mathrm{mm} 2$ to help bridge the cracks in case of further movement and is also corrosion resistant and will remain protected in future even though it is embedded in a highly porous masonry substrate. The materials used were easily transportable, flexible (ie) could be prepared to requirements on site and could be delivered to site quickly despite this being imported. The approach taken resulted in a rapid reinstatement of the building, minimised the risk of losing heritage features and matched the client's overall objectives. The paper provides details of the approach taken and the basis for the remedial intervention.
\end{abstract}

Keywords: Masonry, Structural Cracking, Remedial Intervention, Glass Fibre Materials.

\section{Introduction}

\subsection{Project Background}

A masonry shop house in Taiping, Perak in Malaysia was badly affected by construction being undertaken at an adjacent lot. There was significant evidence of settlement at the front and back of the building, leading to significant cracking of a party wall, front and rear walls and the main walkway Arch Supporting the upper floor and wall.

The building is a 2 storey pre-war shop house with an overall layout plan as shown in Figure 1. The building housed a family business until adjacent construction activity forced the owners to move from the premises due to an eviction order imposed by the local authority arising from the dangerous state of the building. The actual construction details of the adjacent building was not made available but the site visit confirmed that the original 2 storey building next door had been torn down to make way for a 3 storey structure on piled foundations with a lift at the rear. 


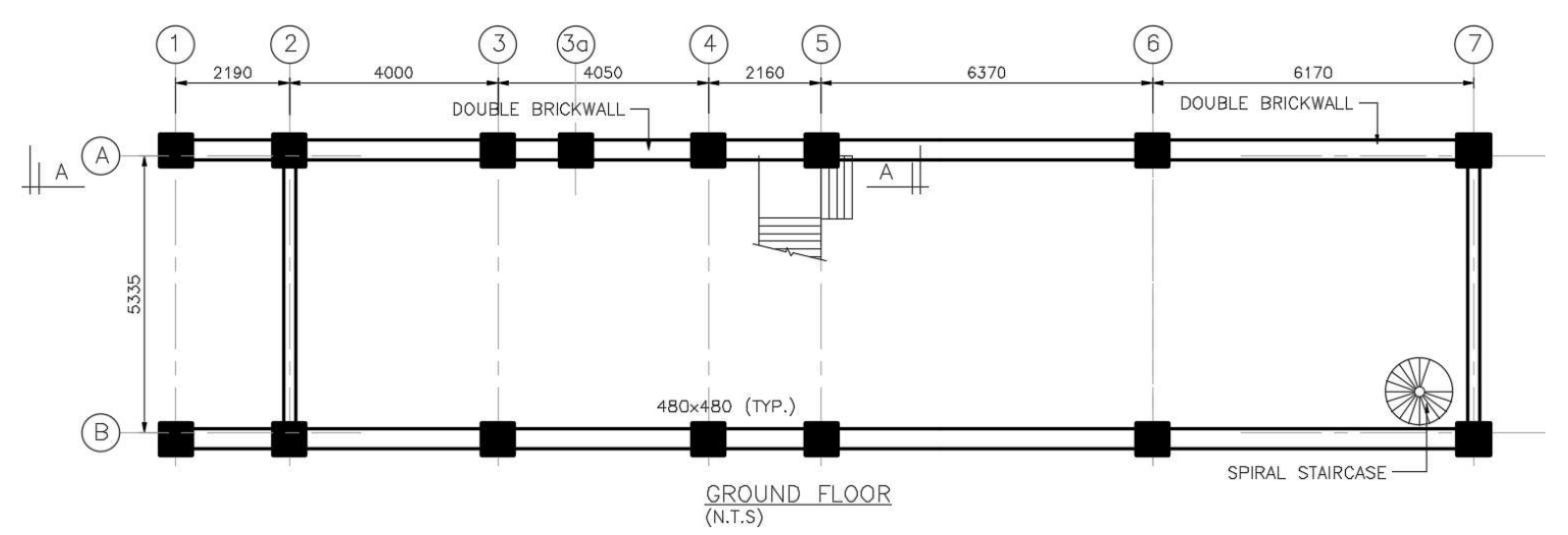

Figure 1. Plan View of Shop House.

The only precaution taken to protect the shop house was an attempt to support the common corridor arch at the front of the building with Timber Props which was totally inappropriate for a structural masonry arch and had potentially accentuated the serious damage caused by imposed stress concentrations due to the settlement and vibration. The structural Engineer who designed the new adjacent 3 storey shop house was asked by the local authority to provide a report and a basis for remedial intervention. The initial suggested approach to epoxy inject the cracks were considered wholly inadequate and not a serious measure of what was required to reinstate the shop house to its original design intent and to guard against long term settlement and cracking

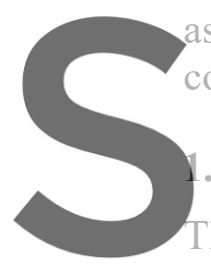
associated with the dist condition of the structure

2 Condition Audit

There was considerable
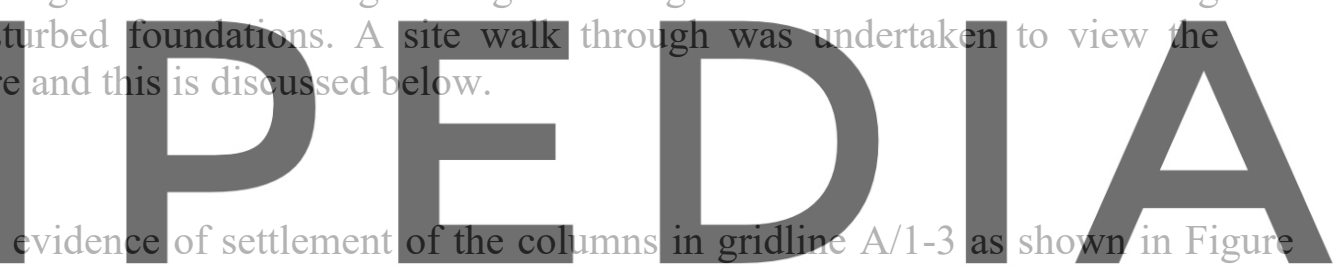

2. This led to uneven loads on the masonry columns causing the characteristic structural cracking of

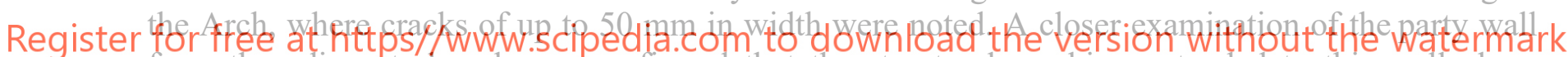
from the adjacent shop house confirmed that the structural cracking extended to this wall along Gridline A2- A5 where cracks of up to $30 \mathrm{~mm}$ were noted. In general the party wall away from the new development was structurally intact. An immediate intervention was proposed to structurally reinstate the front Arch, the common party wall along gridline A and other settlement and cracking points. It was noted that the building was not loaded with the full complement of live loads which can be expected. The cracking on the walls and the Corridor Arch were clearly to do with settlement and vibration loads associated with the adjacent construction, rendering the building unsafe to use at the time of the investigation. There was also a considerable amount of water ingress into the building particular at gridline A-B'/5-7 and also at the building corners at gridline A1 and A5 which had not been a problem previously. Based on the visual survey the key defects noted are summarised in Table1. 


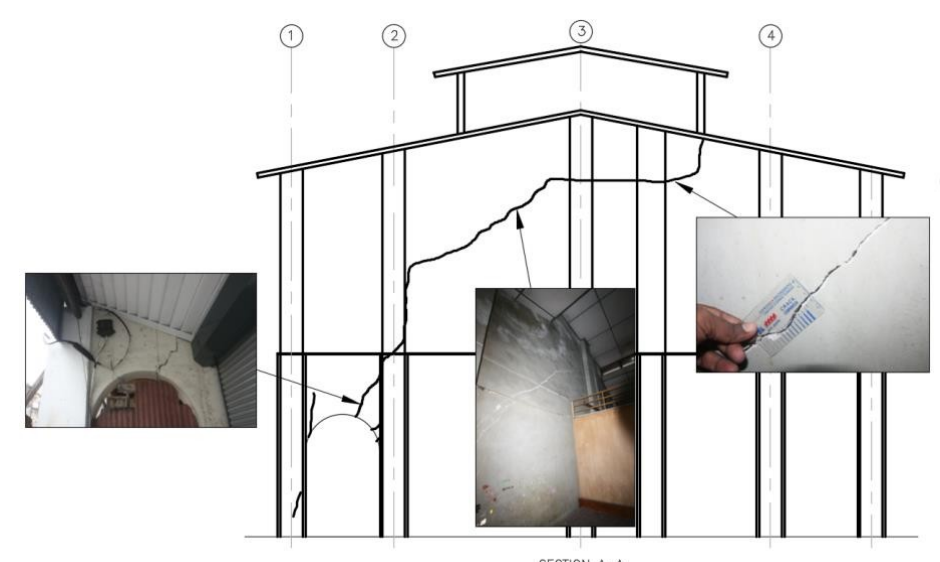

SECTION A-A

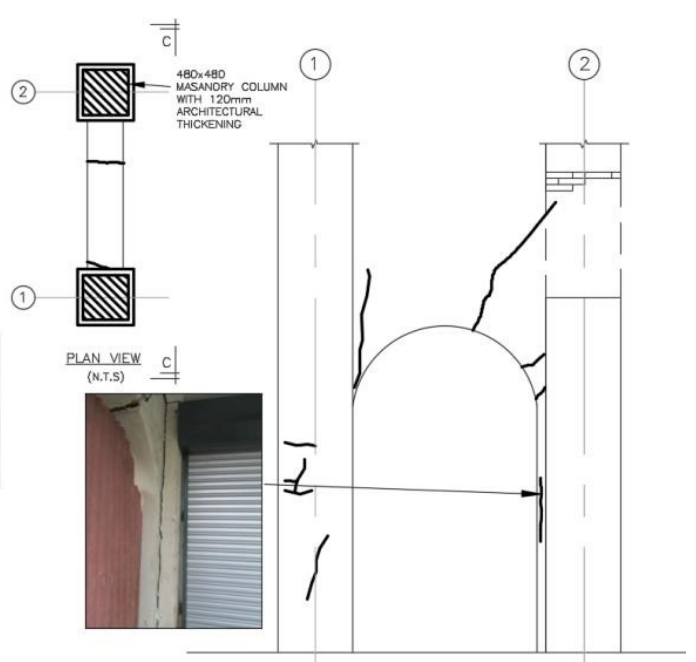

$\operatorname{sectinn} c-c$

Figure 2. A Record of the defects at the Main Arch at the Shop House Front and at the Party Wall.

\section{Engineering Features}

\subsection{Overview}

Demolition of masonry shop houses and rebuilding is often considered the preferred option when such structures come into disrepair. Incroasingly however repair and refurbishment is seen as a more sustainable option in terms of architectural value, materials use, neighbourhood disruption, waste disposal and overall cost. By avolding expensive demolition and rebuild, the development of repair and refurbishment techniques retains the aesthetic and historic value of a bailding including its appearance and providing a sustainable structural solution. It also potentially reduces costs,

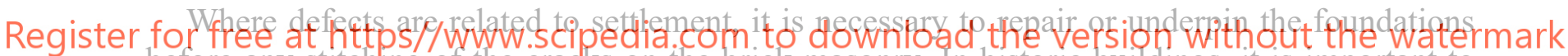
before any stitching of the cracks on the brick masonry. In historic buildings, it is important to preserve as much of the original materials as possible and consider repair options which are relatively reversible and do not damage the original building fabric.

\subsection{Options for Structural Reinstatement}

The building was in a serious state of disrepair and on the verge of collapse. Temporary propping and a stoppage of adjacent works had to be imposed. A rapid approach was critical for the intervention, with materials and methodologies selected to incur minimum additional impacts on the building in terms of physical works and with flexibility on site. 
Table 1. Summary of Condition Audit Findings.

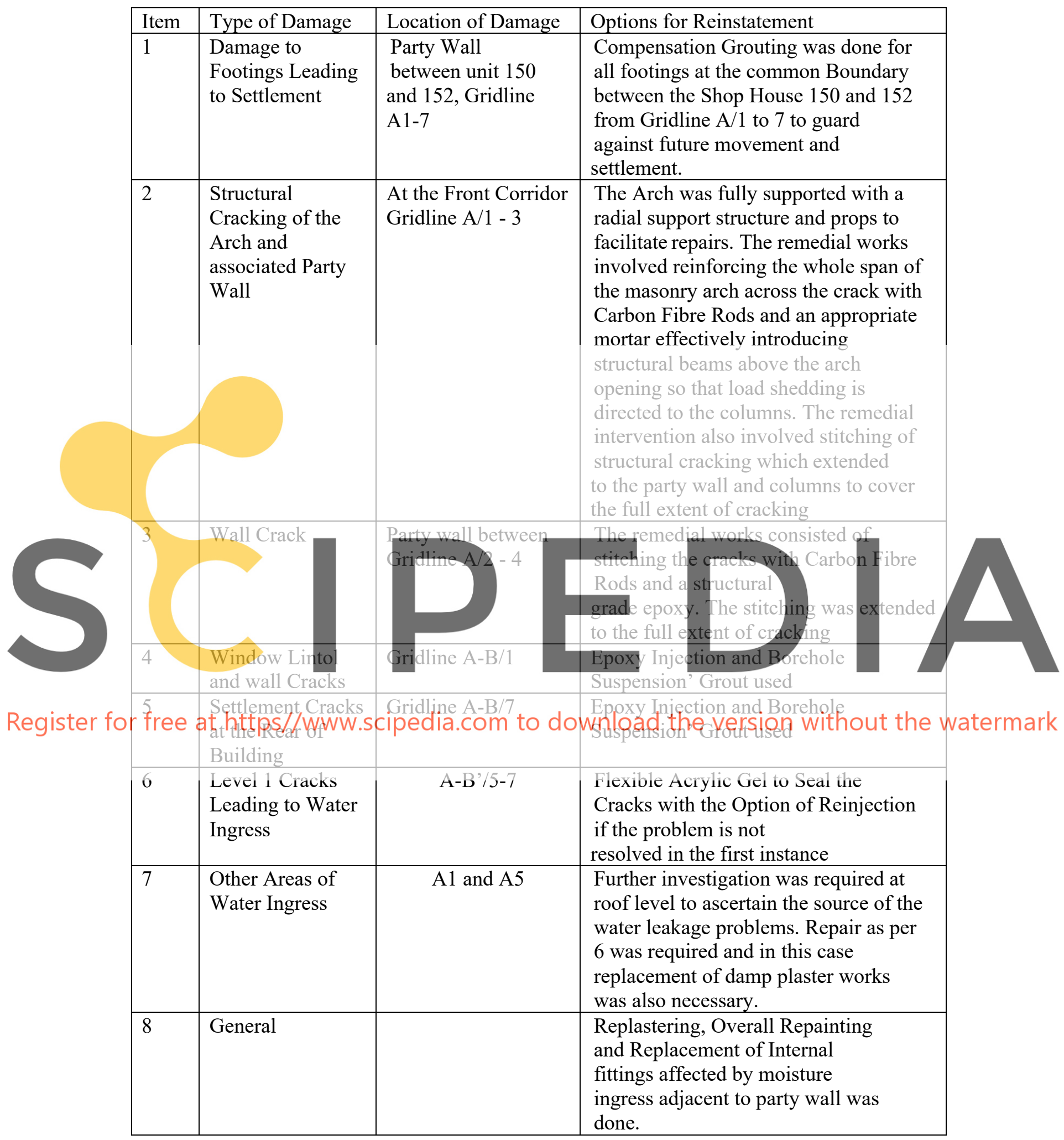


Several innovative techniques have been developed for the structural intervention of masonry buildings. Among the key developments in this area includes the use of stainless steel helical ties and slim ties developed by Helifix (www.helifix.com). These form very strong axial ties to resist lateral forces, yet are flexible enough to accommodate natural building movement without introducing further stresses in the substrate. The associated concealed, non-disruptive installation techniques provide many outstanding benefits, from the simplicity of their design to ease of installation and their long term performance. At the time of the investigation the options for repair had been further advanced by Mapei using alternative materials with glass fibre as the base ie Maperod G and Mapewrap Foccio. Where masonry wall cracks are to be repaired by a stitching method, the glass fiber rod maperod $\mathrm{G}$ is a suitable material due to the compatibility of modulus of elasticity $(40,800 \mathrm{~N} / \mathrm{mm} 2)$ to the lime mortar. It also has a good tensile strength of 760 $\mathrm{N} / \mathrm{mm} 2$ to help bridge the cracks in case of further movement. As glass fiber is also corrosion resistant it will be protected in future even though it is embedded in the highly porous masonry substrate. In the case of the Taiping shop house the latter approach i.e Mapei rod was used as the materials were easily transportable, flexible i.e could be prepared to requirements on site, and Mapei had the infrastructure to deliver the materials to site quickly despite this being imported.

\subsection{Approach to Reinstatement}

The extent of the remedial works was confirmed based on the visual examination and following hammer tapping and hacking to confirm the extent of the problem. The final remedial works undertaken between gridlines 1-5/A included the following:

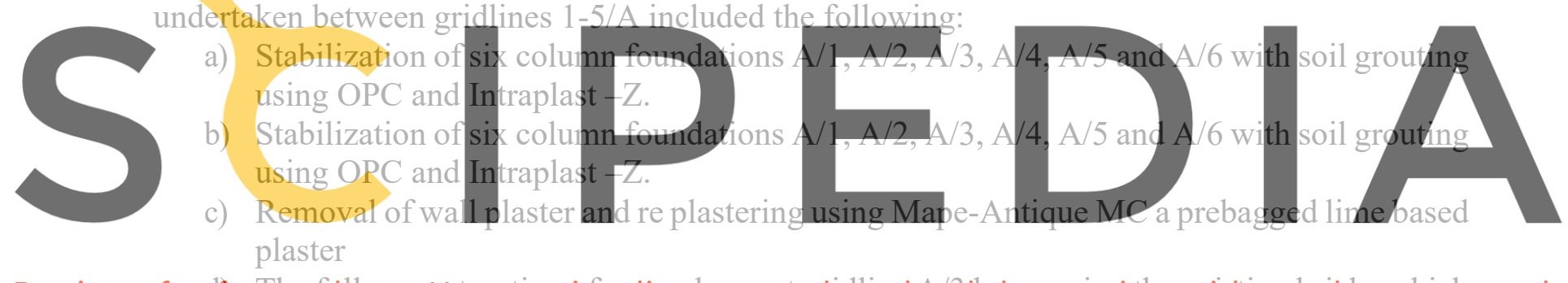

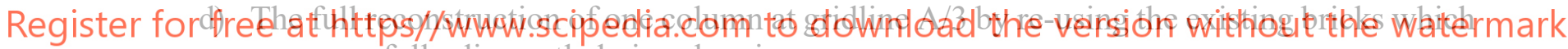
were carefully dismantled piece by piece.

e) The columns at gridline $\mathrm{A} / 2$ and A/5 were partially removed and the bricks reinstated and injected using Mape-Antique I by a low pressure injection method.

f) The Arch and wall cracks were repaired by a stitching method using Maperod G a glass fibre rod which is inert within the matrix but providing structural strength.

g) Mapewrap G Fiocco was used allowing stitching to be performed at one-side with minimum impact to the overall wall with the anchors planted deep into the masonry wall to provide the full anchorage.

In this case the stitching could only be performed at one-side and for this reason Mapewrap G Fiocco was selected as an appropriate method. Mapewrap G Fiocco is made into an L-shaped anchor using epoxy impregnator Mapewrap $31 \mathrm{SP}$ and is bonded at both ends of the Maperod G.

The anchor is planted deep into the masonry wall, ie approximately to a depth of $140 \mathrm{~mm}$ to provide the full anchorage. To structurally bond the Maperod G and Mapewrap Fiocco to the masonry wall, epoxy adhesive Adesilex PG2 TG was selected. Epoxy has high durability and good mechanical properties in terms of compressive, flexural, tensile and shear strength. 
To enhance the bonding to the masonry wall, all contact surfaces of the masonry were primed with Mapewrap Primer 1 SP to consolidate the porous surface and eliminate dust. The crack lines were reinforced at every 4-5 brick intervals and inserted into the pointing layer for a minimal impact on the existing masonry wall. The full extent of the repairs is illustrated in Figure 3.

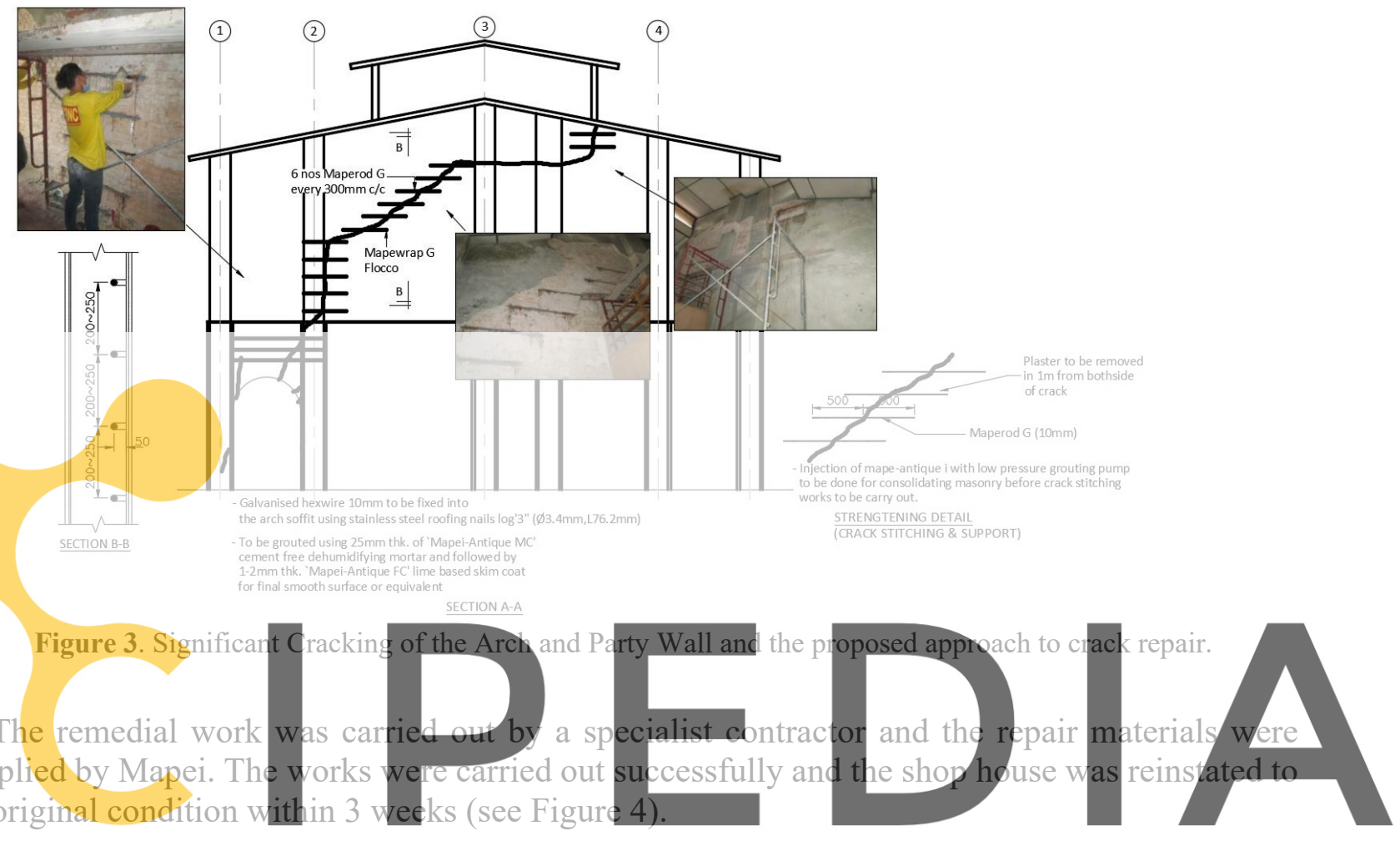

Register for free at https//www.scipedia.com to download the version without the watermark
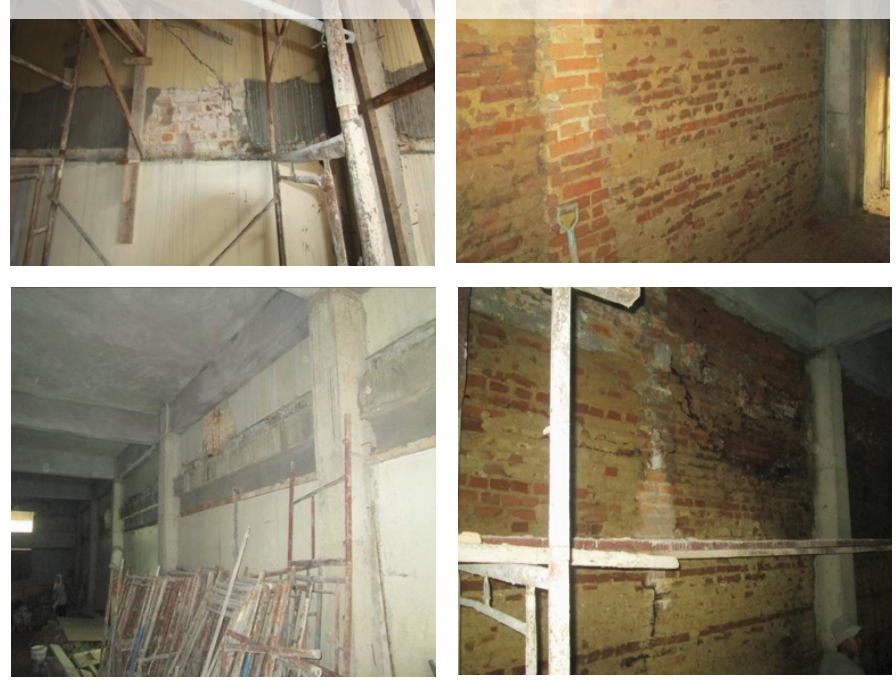

Figure 4. Additional Illustrations of the Remedial works. 


\section{Project Accomplishment}

\subsection{Client Needs}

The remedial works were undertaken rapidly and reduced the impact of the loss of access to the facility. The alternative which was on the cards was demolition and rebuilding. The engineering solution entailed using modern materials developed specifically for heritage upgrading which had never been used in a practical project application before for structural restoration. The work was done with little impact on the overall heritage value of the building.

\subsection{Budget and Project Time Line}

The project was successfully controlled with the implementation of proper documentation in the form of detailed method statements and pre-selection of materials to be used directly from a specialist supplier (Mapei). In conjunction with Mapei an off-site training was undertaken of key personnel involved in the project to minimise delay on site.

The arches and key structural components had been temporarily propped using specially designed timber props to guard against collapse and this was removed progressively. The stabilization of the foundation was undertaken within a week and as the injection works were completed in a particular area masonry strengthening works proceeded in the associated area. The crack repair works and stabilisation of the masonry walls proceeded over a 2 week period. The

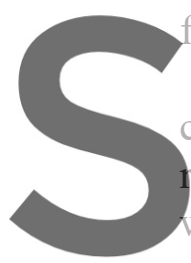
finishing works and pain

The works were succes compared to rebuilding esponsibility of the adjacent works contractor win-win for all parties (ie) in terms of time and
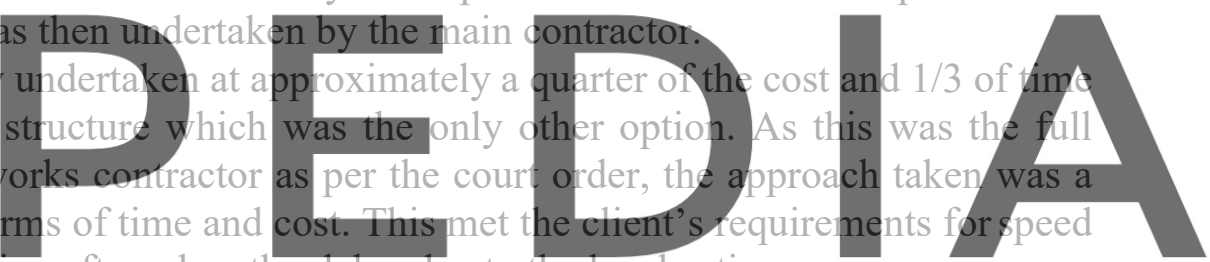

and minimisation of the disruption after a lengthy delay due to the legal action.

Register for freen.athttps//www.scipedia.com to download the version without the watermark

This work demonstrated the validity of the use of modern materials for a non-invasive low maintenance reinstatement of a heritage building badly affected by settlement and structural movement with little impact on its heritage value. This was considered to be the most costeffective solution and appropriate, where speed of reinstatement to manage structurally compromised masonry buildings are concerned. As the structural rods used in strengthening are made with glass fibre reinforcement these are not affected by corrosion which is a problem in porous Masonry structures particularly if rebars are used for strengthening. In this case life cycle issues outweighed initial capital expenditures particularly as a period building was concerned and the approach minimised the risk of any repeat intervention which would have in a rapid reinstatement of the building, minimised the risk of losing heritage features and matched the client's overall objectives. 


\subsection{Budget and Project Time Line}

The project was successfully controlled with the implementation of proper documentation in the form of detailed method statements and pre-selection of materials to be used directly from a specialist supplier (Mapei). In conjunction with Mapei an off-site training was undertaken of key personnel involved in the project to minimise delay on site.

The arches and key structural components had been temporarily propped using specially designed timber props to guard against collapse and this was removed progressively. The stabilization of the foundation was undertaken within a week and as the injection works were completed in a particular area masonry strengthening works proceeded in the associated area. The crack repair works and stabilisation of the masonry walls proceeded over a 2 week period. The finishing works and painting was then undertaken by the main contractor.

The works were successfully undertaken at approximately a quarter of the cost and $1 / 3$ of time compared to rebuilding of the structure which was the only other ontion. As this was the full responsibility of the adjacent works contractor as per the court order, the approach taken was a win-win for all parties (ie) in terms of time and cost. This met the client's requirements for speed and minimisation of the disruption after a lengthy delay due to the legal action.

\subsection{Overview}

This work demonstrated the validity of the use of modern materials for a non-invasive low maintenance reinstatement of a heritage building badly affected by settlement and structural movement with little in effective solution and compromised masonry buildings are concerned. made with glass fibre reinforcement these are porous Masonry structures particularly if rebars a
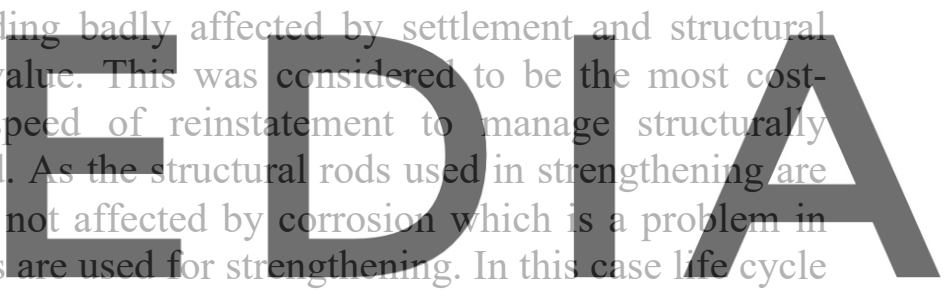

issues outweighed initial capital expenditures particularly as a period building was concerned and

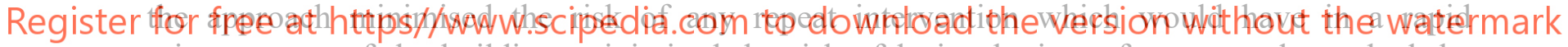
reinstatement of the building, minimised the risk of losing heritage features and matched the client's overall objectives.

\section{ORCID}

Kribanandan Gurusamy Naidu: https://orcid.org/0000-0002-6782-594

\section{References}

Avdeeva, A., Shlykova, I., Antonova, M., Baraanschikov, Y. and Belyaeva, S. (2016). Reinforcement of concrete tructures by fiberglass rods. (Russia), St. Persburg State Polytechnical University, St Petersburg, Russia.

Jarek, B. and Kubik, A. (2015). The Examination of the Glass Fiber Reinforced Polymer Composite Rods in Terms of the Application for Concrete Reinforcement. Procedia Engineering, 108, 394 - 401.

Sheppard, P. and Tercelj, S. (1980). The effect of repair and strengthenings method for masonry walls. Proceedings 7th WCEE, 6, 255 Istanbul.

Plecnik, J.M., Corsins, T. and O'Conner, E. (1986). Strengthening of Unreinforced Masonry. Journal of structural engineering ASCE, 112(5), 1070-1087. 